\title{
Grammatical Flexibility as a Resource in Explicating Referents
}

\author{
Galina B. Bolden \\ Department of Communication \\ Rutgers University \\ Estefania Guimaraes \\ Department of Sociology \\ University of York, United Kingdom
}

\begin{abstract}
This article examines one aspect of interplay between grammar and social interaction: how speakers of different languages explicate referents that had been referred to tacitly, i.e., without using an explicit referential expression. The focus is on situations when speakers go on to explicate the referent in the transition space, after bringing the turn constructional unit to a possible completion. Depending on the grammatical affordances of the language, rendering a tacit reference explicit may either expose or mask this operation. Focusing on the latter, we show that the grammars of Russian and Brazilian Portuguese (and, to a lesser extent, English) enable speakers of these languages to explicate referents by extending a possibly complete turn constructional unit with a grammatically fitted increment and, thereby, embed this remedial operation into the progressive construction of the turn without engaging repair machinery. We discuss how tacit referring and flexible word order can enable speakers to carry out this repair-like operation in a covert or embedded fashion, and we examine some interactional functions of this referent-explicating operation.
\end{abstract}

This article examines one aspect of interplay between grammar and social interaction: how speakers of different languages explicate referents that had been referred to tacitly. By tacit referring, we mean referring that is accomplished not overtly with an explicit referential expression (e.g., an indexical or a full reference form), but tacitly, as in Excerpts A and B.

\section{Excerpt A}

Bee: they can't delay much lo:nguh

\section{Excerpt B}

Emm: =.hhh Jis got down last nị:ght.

Correspondence should be sent to Galina B. Bolden, Department of Communication, Rutgers University, 4 Huntington Street, New Brunswick, NJ 08901-1071. E-mail: gbolden@rci.rutgers.edu 
In Excerpt A, what "can't [be delayed] much lo:nguh," and, in Excerpt B, who "jis got down last ni:ght" are not articulated explicitly. Rather, the addressees are expected to understand the implied referent based on the particulars of the context. In linguistics, the phenomenon of tacit referring - the possibility of eliding references to grammatical complements of a verb-is ordinarily termed "zero anaphora" (Oh, 2005, 2006, 2007; Ono \& Thompson, 1997) or "zero" reference ${ }^{1}$ (e.g., Levinson, 2007).

This article focuses on situations when interlocutors go on to explicate referents that had been referred to tacitly, in the transition space, after they bring the turn constructional unit (TCU) to a possible completion (Sacks, Schegloff, \& Jefferson, 1974). Depending on the grammatical affordances of a particular language, rendering a tacit reference explicit may either expose or mask this repair-like operation. Focusing on the latter, we will show that the grammars of Russian and Brazilian Portuguese (and, to a lesser extent, English) enable speakers of these languages to explicate referents that had been tacitly referred to by extending a possibly complete turn constructional unit with a grammatically fitted increment (e.g., Ford, Fox, \& Thompson, 2002; Schegloff, 2000). ${ }^{2}$ In this way, the operation of explicating a tacit reference is embedded into the progressive construction of the turn and does not engage repair machinery.

For one preliminary English-language illustration of the phenomenon under investigation, see Excerpt 1. Bee and Ava have been talking about their school schedules. At line 4, with "I didn' know what day:s you had," Ava tacitly refers to Bee's schedule (e.g., "I didn't know what days you had your classes"). This constitutes a possibly complete turn constructional unit since, in this sequential environment, "I didn' know what day:s you had" is a grammatically complete construction that accomplishes a recognizable action (in fact, Bee goes on to respond to it in lines 5-6). Furthermore, Ava produces this unit of talk with a unit-final falling intonation (marked by the period in line 4), which also indicates the unit's possible completion (Ford \& Thompson, 1996).

Excerpt 1: Classes or Anything

TG (8:45)

$01 \quad$ Bee: Mm, tch! I wz gonnuh call you. last week someti(h)me

02 hhh[hh!

03 Ava: [Yeh my mother a : sked mih I siz I don'know I haven't

$04>\quad$ hea:rd from her. I didn' know what day:s you had. $\mathrm{h}[\mathrm{hh}$

05 Bee: [Yeh

$06 \quad$ en I [: didn' know w- $]$

$07>$ Ava: [ cla:sses 'r ] a [nything,

08 Bee: $\quad$ [I didn'know when you were hh [ome=

09 Ava: [Tch!

\footnotetext{
${ }^{1}$ See Ono and Thompson (1997) for a critical discussion of the term "zero anaphora." "Zero reference" is a broader term, as, unlike "zero anaphora," it does not invoke a previous mention of the referent. In some languages, initial references (to persons) may be accomplished tacitly, or with zero reference (e.g., Levinson, 2007). In languages considered here-English, Brazilian Portuguese, and Russian - tacit referring is mostly done in locally subsequent positions (one exception may be the first person reference "I," which can often be elided). Depending on the researcher's theoretical orientation and analytic goals, similar phenomena may be referred to as pro, subject/object ellipsis, unexpressed, omitted or null subject/object, etc. (e.g., Holmberg, 2005; McShane, 2002).

${ }^{2}$ We are adopting Schegloff's (1996b, 2000) definition of increments as grammatically fitted extensions of the host turn constructional unit. Ford et al. (2002) refer to such increments as "extensions." On the other hand, what Ford et al. call "free constituents" - another category of "increments" in their scheme—are not considered "increments" here.
} 
Following her possibly complete TCU at line 4 (and in overlap with Bee), Ava takes an inbreath and then extends her turn with a grammatically fitted increment "cla:sses 'r anything" (line 7). This increment explicates what had been tacitly referred to in the host TCU (at line 4) and the final product - "I didn' know what day:s you had. 'hhh cla:sses 'r anything" —is again a possibly complete unit (see Schegloff, 1996b, for a discussion of this segment). In explicating the referent, the speaker relies on turn constructional resources (producing a grammatical continuation of a TCU that has been brought to a possible completion) rather than engages repair machinery. Specifically, "cla:sses 'r anything" is not a "repair solution" (Schegloff, Jefferson, \& Sacks, 1977) but an incremental extension of the host TCU. Note that the speaker does not initiate repair on her prior TCU (with, for example, "I mean ...") and thus does not expose a problem in the host TCU. Further, "cla:sses 'r anything" is not produced as a response to a repair initiation by the addressee (such as, "What" or "What do you mean"; cf. Egbert, Golato, \& Robinson, 2009). Overall, Excerpt 1 shows that a repair-like operation of explicating a referent can be accomplished in a covert - or embedded - fashion. In other words, this method of explicating a reference is akin to what Jefferson (1987) called embedded (rather than exposed) correction: i.e., correction that is done as part of the ongoing talk, without the activity of correcting coming up to the conversation's surface. While Jefferson focused on embedded other-correction, we will describe how speakers remediate their own preceding talk in an embedded fashion.

In the following, we first provide background on grammatical resources of Russian and Brazilian Portuguese that play a role in how tacit references get explicated and contrast them with English. We then demonstrate how referent explication is deployed in interaction and discuss some interactional functions of this operation. The findings presented here are based on our analysis of several corpora of audio or video recorded, naturally occurring everyday and institutional interactions, both telephone and face-to-face, in English, Russian, and Brazilian Portuguese.

\section{LINGUISTIC RESOURCES FOR EXPLICATING TACIT REFERENCES}

In this section, we provide a brief linguistic background on grammatical features of Russian and Brazilian Portuguese that allow speakers of these languages to carry out the repair-like operation of referent explication covertly (i.e., without engaging the machinery of repair) and compare them to the linguistic resources available to speakers of English. Two features of Russian and Brazilian Portuguese are particularly relevant: first, the wide availability of tacit referring and second, the flexibility of the word order.

\section{Tacit Referring}

Referring to persons, places, objects, etc., tacitly-i.e., without using an overt or explicit referential expression-is a common conversational practice. Languages, however, have different affordances for what can be tacitly referred to and what has to be explicitly articulated. In English, tacit referring is possible in certain grammatical and sequential environments, as illustrated by Excerpts 2 and 3. In Excerpt 2, the highlighted sentential TCU does not contain an explicit grammatical object: "they can't delay [what] much lo:nguh" (line 6). In Excerpt 3, the sentential TCU at line 5 does not contain an explicit grammatical subject: jis got down last ni:ght" (see Oh, 2005, 2006). 
Excerpt 2 (A expanded): The Operation (TG)

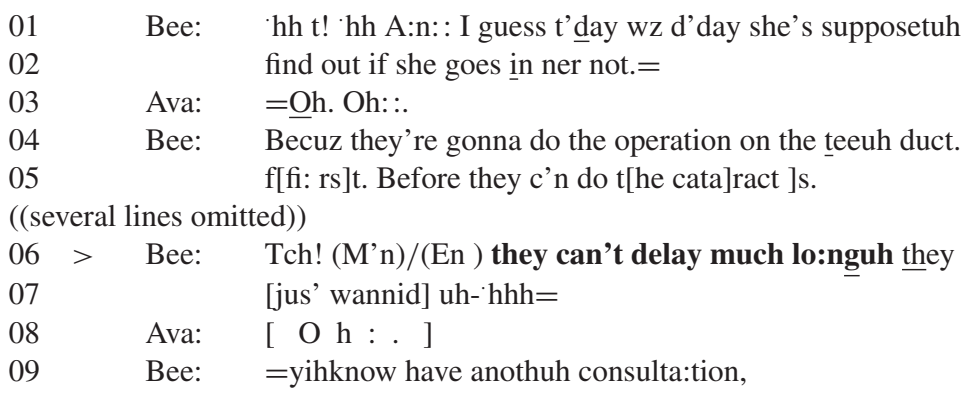

Excerpt 3 (B expanded): Just Got Down (NB:II:3:R)

01 Emm: G'morning Letitia $=\quad(($ smile voice $))$

02 Lot: =u.-h $\underline{\text { How'r YOU: }}=$

03 Emm: =FI : NE HOW'R [YOU :

04 Lot: [eh he $\underline{\text { :h heh WUDIYIH kno:w.= }}$

$05>$ Emm: =.hhh Jis got down last ni:ght.eh

06 Lot: OH YOU DI [ $: \overline{\mathrm{D}}$ ?

07 Emm: ['hhh We BEEN tuh PA:LM SPRI:NGS.

Yet, in each case, the recipient unproblematically understands what or who is being referred to, as evident from the responses: the change-of-state token "oh:" in Excerpt 2 (line 8) and the news receipt “OH YOU DI:D?” in Excerpt 3 (line 6) (Heritage, 1984; Jefferson, 1981).

Yet, the use of tacit (over explicit) referring is not simply guided by "understandability" of a referent in context. Grammars impose constraints on speakers' choices so that even completely "understandable" referents may have to be explicitly articulated (cf. Holmberg, 2005). In English, while tacit referring is possible, it is rather restricted. For example, many English verbs grammatically require an explicit referential expression in the grammatical object slot $^{3}$ (e.g., McShane, 2002), and, for the most part, sentential TCUs require an explicit reference in the grammatical subject slot (however, see Oh, 2005, 2006). In some other languages (such as Russian and Brazilian Portuguese), tacit referring is more prevalent. For instance, in Russian and Brazilian Portuguese, one can often omit an explicit reference in the grammatical object slot ${ }^{4}$ (e.g., Cyrino, 2004; Cyrino \& Matos, 2002; Gordishevsky \& Avrutin, 2003; McShane, 2002), as illustrated by Excerpt 4 (for Russian). Prior to this extract, the two interlocutors have been talking about the terms of the apartment lease that Dima's son has. At line 1, Dima asks a reciprocal question about Yasha's apartment lease, referring to "the lease" tacitly. (On the transcript, the implied indexical reference is placed in curly brackets in the translation line. The Russian language transcription conventions are described in Bolden [2009].)

\footnotetext{
${ }^{3}$ In linguistics, this is known as "obligatory transitivity"- the requirement that the direct object of the verb be overtly expressed.

${ }^{4} \mathrm{~A}$ discussion of conditions under which this may be possible is beyond the scope of this article. For linguistic accounts of object omission in Russian see, for example, Gordishevsky \& Avrutin (2003) and McShane (2002); for Brazilian Portuguese, see Cyrino (2004) and Cyrino \& Matos (2002).
} 
Excerpt 4: Lease [Russian]

RP1 (5:50)

01 > Dima: Kagda ani dalzhny pradljat'ta/ when they must renew PRT When should they renew \{it\}

02

$(0.8) /\{. h h\}$

03 Dima: [\#eh

04 Yash: [V ijune pamojmu/

in june I-think

In June I think

In line 1, referring to the lease is accomplished tacitly, with no explicit referring expression used ("renew \{the lease\}"). Note that Yasha displays his understanding of Dima's question by responding to it (at line 4).

Excerpt 5 is a parallel Brazilian Portuguese example. As context, a police officer (Po7) needs to $\log$ on to the computer with his password so that he can start a police report. The officer is about to leave the room (line 4) to get a password, which he had not received. At line 5, another police officer (Po6) asks about the password, referring to it tacitly: "You don't have \{one\}?"

Excerpt 5: Password [Portuguese]

WPS 25

01 Po7: Eu tenho que pegá poque eu tô: sem a senha aí

I have to get because I am without the password there

I have to get $\{$ it $\}$ because I am without this password for

02 desse negócio aí:.

for+this business/thing there

this thing there.

03

(.)

04 Po7: A senhora dá licença.

The ma' am give excuse.

Would you excuse me ma'am.

05 > Po6: Cê num tem não é?

You no have no is

You don't have \{one\}?

06 Po7: Não. Eu tenho mas ninguém me deu ainda.

No. I have but nobody me gave yet.

No. I have $\{$ it $\}$ but nobody gave $\{$ it $\}$ to me yet.

In line 6, Po7 understands and responds to the question (at line 5) and, notably, also refers to the password tacitly. 
In Russian and Brazilian Portuguese, along with many other so-called pro-drop languages, ${ }^{5}$ one can also often omit an explicit reference in the grammatical subject position (e.g., Duarte, 2003; Grenoble, 2001; Kato, 2000; Magalhães \& Santos, 2006; Zdorenko, 2009). In Russian and Brazilian Portuguese, verbs carry a lot of information about the grammatical subject of the sentence (for example, whether it is in the first, second, or third person; singular or plural; and, in Russian, grammatically masculine, feminine, or neutral), which facilitates understanding of tacit references. ${ }^{6}$ In fact, in these languages, tacit referring may be what Schegloff (1996a) calls the "referring simpliciter"-i.e., an unmarked reference form that accomplishes nothing more than simply referring. This unmarked usage of tacit referring in pro-drop languages is consistent with the preference for minimization in the domain of person reference (Hacohen \& Schegloff, 2006; Oh, 2007; Schegloff, 1996a, 2007).

A Russian language example of this is Excerpt 6. Following a question about her mom, Tanya simply responds "still sick" (line 3) without explicitly articulating who is being referred to.

\section{Excerpt 6: Still Sick [Russian]}

\begin{tabular}{|c|c|c|}
\hline \multicolumn{3}{|c|}{ RP4 (5:20) } \\
\hline 01 & Dina: & $\begin{array}{l}\text {.hh Slu[shaj Tan'ka (.)] Tanya a kak mama ta/ } \\
\text { listen NAME NAME and how mom PRT } \\
\text { Listen Tanya Tanya how is your mom }\end{array}$ \\
\hline 02 & & $\{1.0\} /\{. \mathrm{hhh}\}$ \\
\hline $03->$ & Tan: & $\begin{array}{l}\mathrm{Da} \uparrow \text { bale:et } \downarrow \text { eschë vsë/ } \\
\text { PRT be-sick [ } 3^{\text {rd }} \text {-Sing] still all } \\
\text { \{She\} is still sick }\end{array}$ \\
\hline 04 & & (.) \\
\hline 05 & Dina: & $\begin{array}{l}\text { Nu palu } \text { icchshe/ }_{\text {ch }} \\
\text { PRT better } \\
\text { But \{she\}'s better? }\end{array}$ \\
\hline
\end{tabular}

The Russian verb bale:et ("is sick") is morphologically marked for the third-person singular (i.e., he or she). This, together with the sequential environment of Tanya's turn, makes the referent "she" (or "the mom") easily inferable. Note that Dina treats Tanya's response as unproblematic and (at line 5) launches a follow-up question (again, referring to the mom tacitly).

In Excerpt 7 (in Brazilian Portuguese), a police officer (Po2) is compiling a police report for a battery incident perpetrated by the complainant's (Com) ex-partner. At line 4, the police officer asks another question in a series of questions about the perpetrator, referring to the perpetrator tacitly.

Here tacit referring relies both on the sequential placement of the question (in a series of questions about the perpetrator) and on the information conveyed morphologically by the verbal

\footnotetext{
${ }^{5}$ There is some theoretical debate about the status of Russian and Brazilian Portuguese as "true" pro-drop languages (e.g., Gordishevsky \& Avrutin, 2003; Holmberg, 2005). There is no question, however, that these languages allow omission of grammatical subjects in some environments. A discussion of these environments is, however, beyond the scope of this article.

${ }^{6} \mathrm{~A}$ comparison with languages like Japanese or Korean suggests that the prevalence of tacit referring is only partially due to a language's morphological richness (Fox, Hayashi, \& Jasperson, 1996; Holmberg, 2005).
} 
Excerpt 7: Was He Drunk [Portuguese]

WPS10

01 Po2: Qual ba:irro.

What neighbourhood.

02 Com: Enge:nho.

((Name of a Neighbourhood))

03

(3.8) ((typing))

04 Po2:

Tava bê:bado.

Was $\left[1^{\text {st }} \& 3^{\text {rd }}\right.$ p.s. $] \operatorname{drunk}(M)$.

Was $\{\mathbf{h e}\}$ dru:nk.

05 Com: N:ão.

N:o.

phrase tava bêbado ("was drunk"; see especially the masculine marking on bê:bado/"drunk," line 4). Observe that the complainant responds immediately (line 5), thus demonstrating that she unproblematically understood who is being talked about.

The foregoing discussion has illustrated the use of tacit referring in English, Russian, and Brazilian Portuguese talk-in-interaction and suggested that in Russian and Brazilian Portuguese, tacit referring is a very common—and perhaps unmarked—practice for achieving referring.

\section{Flexible Word Order}

The second feature of Russian and Brazilian Portuguese relevant to the discussion at hand is the relatively flexible word order in these languages (e.g., Silva, 2001; Yokoyama, 1986). In both languages, the default "subject-verb-(object)" word order can be modified in various ways, such as having the subject located at a TCU-final position. ${ }^{7}$ As will be shown subsequently, flexible word order makes it possible to explicate a referent that had been referred to tacitly via a grammatically fitted increment to the current TCU, without exposing this operation as repair. In this section, we briefly illustrate this characteristic of Russian and Brazilian Portuguese grammars by presenting instances of speakers placing grammatical subjects in TCU-final (rather than the default TCU-initial) positions.

In Excerpt 8 from a conversation between Russian immigrants in the U.S., Dad is talking about the failure of the Republican Party at the recent presidential elections. There are two instances of grammatical subjects in a TCU-final position: "Bush" at line 1 and "Americans" at line 4. Both of these are grammatically appropriate in Russian. (Note that "Bush" at line 3 is not a TCU-final subject but a repair solution for the indexical on ["he"] at line 2.)

\footnotetext{
${ }^{7}$ Linguists studying Russian (e.g., Turk, 2000; Yokoyama, 1986) and Brazilian Portuguese (e.g., Silva, 2001) argue that word order in these languages relates to the information structure of discourse (specifically, the distinction between "old" versus "new" information). To our knowledge, no interactional studies on word order in either Russian or Brazilian Portuguese have been conducted. A discussion of what constitutes an "underlying" word order in these languages or of the interactional functions of word order is beyond the scope of this article.
} 
Excerpt 8: Bush [Russian]

M1-2 (28:30)

01 DAD: [Patamushta- (.) A vinavat va vsëm Bu:sh/

because PRT blamed in all LAST_NAME

Because- Bush is to blame for everything

02 Patamushta ix- vtaroj s:rok on stol'ka tam

because second term he so_much there

Because- During the second term he

03

napaga, ,il/=Bush/ (0.4)

spoiled LAST_NAME

messed up so much Bush

04 shto paetamu uzhe us:tali at nevo Amerikancy/

that because already tired from him Americans

that Americans got tired of him

Excerpt 9 (in Brazilian Portuguese) is from an interaction between a complainant and a police officer and also features a grammatical subject in a TCU-final position (line 7).

Excerpt 9: Police Report [Portuguese]

WPS 18

01 Po1: $\quad$ Então eu já tenho-=(ele tem) registro aqui:.

So I already have he has) register here

So I've already got-=(he has) a report here.

02 Com: É:=aí só que o menino da procuradoria

Is then only that the boy of the-law-office

Ye:s=but then the guy from the law office

03

mando vim pegá o BO aqui pra levá lá

ordered come to-get the report here to take there

told me to come and get a report here to take there

04

ainda hoje que=eu só tenho até hoje pra

still today that I only have until today to

today cuz $=$ I just have up until today to

05

pra resolvê:

to solve

to solve it.

$06 \quad(2.0)$

$07>$ Po1: $\quad$ Mas já foi registrado esse BO:

But already was registered this report

But this report has already been registered.

08

09 Com: Nã:o.

No

No:. 
At line 7, the police officer attempts to clarify whether a police report had already been filed. This inquiry shows that, in Portuguese, an explicit reference to a grammatical subject ("this report") may be placed in a TCU-final position.

\section{EXPLICATING REFERENTS THAT HAD BEEN TACITLY REFERRED TO}

The two grammatical features of Russian and Brazilian Portuguese discussed above- the wide availability of tacit referring and the flexible word order-have an interactional payoff when it comes to explicating referents: i.e., rendering something that was referred to tacitly explicit. In Russian and Brazilian Portuguese, speakers can explicate referents in a grammatically fitted incremental extension of the host TCU, without exposing this as a repair operation. On the other hand, in languages with less flexible word orders, ${ }^{8}$ such as English, explicating tacit references in the transition space may expose the problem because the added explicit reference may not be grammatically contiguous with the host TCU.

Let's start, however, with a situation in which English parallels Russian and Brazilian Portuguese: when the explicit reference fits into the grammatical object position of a sentential TCU that has been brought to a possible completion, extending it with a grammatically fitted increment. Excerpt 1, discussed in the introduction, illustrates this case. Note that "cla:sses 'r anything," (line 7), which Ava adds incrementally to her host TCU ("I didn' know what day:s you had" at line 4), occupies the slot of a grammatical object of the sentential TCU. The final product-“I didn' know what day:s you had. 'hhh cla:sses 'r anything"-is again a possibly complete unit. In this way, the speaker manages to explicate a referent without exposing a problem in the host TCU.

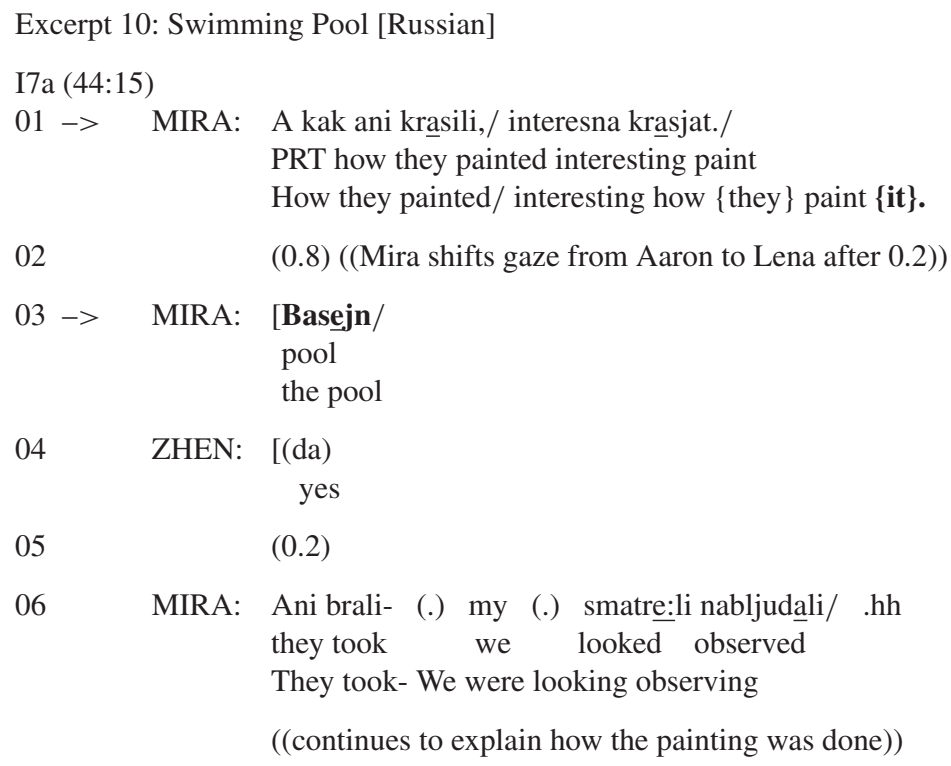

\footnotetext{
${ }^{8}$ For instance, Japanese and Korean freely allow for zero reference, but-as strictly verb-final languages—clearly mark the end of a TCU as such (with sentence-final particles). So, when referring is accomplished tacitly and a TCU is
} 
Excerpt 10 is a parallel case for Russian. Prior to the excerpt, Mira has been talking about an outdoor swimming pool in her apartment complex, which had been recently renovated (data not shown). This excerpt comes from a face-to-face conversation among four participants: Mira, her granddaughter Lena, Aaron, and Zhenya. At line 1, primarily addressed to Aaron via gaze, Mira launches a telling about the painting of the pool.

Line 1, produced with a unit-final falling intonation (marked with a period plus slash), constitutes a grammatically, pragmatically, and intonationally possibly complete TCU in which Mira refers to the swimming pool tacitly. (One piece of evidence that the turn is possibly complete [and understandable] is Zhenya's subsequent uptake of it at line 4, apparently designed to forward the telling.) Having reached a possible completion of her turn, Mira shifts her gaze from Aaron to Lena (during the gap at line 2) and extends her TCU with an explicit full-form reference "the pool" (bassejn at line 3). This extension is a grammatically contiguous increment to the host TCU at line 1; the resulting TCU is translatable as "Interesting how they paint. the pool." Note that the addition of "the pool" does not appear to be engendered by a display of nonunderstanding as, during line 2 , Lena, ${ }^{9}$ Aaron, and Zhenya are simply ("neutrally") gazing at Mira (see Seo \& Koshik, 2010 on nonvocal initiation of repair). Rather, the incremental addition of an explicit reference form is used as a resource to readdress the turn that was initially addressed to one interlocutor (Aaron) to another (cf. Goodwin, 1979).

Excerpt 11 (in Brazilian Portuguese) is from the beginning of an interaction at the police station. Upon entering the room, the complainant tells her young child to close the door (line 3).

Excerpt 11: Porta [Brazilian Portuguese]

01 Po2: $\quad{ }^{\circ}$ Senta ai ${ }^{\circ}$

Sit there

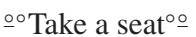

02

03 Com: Fecha aí:. A porta. ((to her child))

Close there. The door.

Close $\{$ it $\}$ the:re. The door. ((or "Close the door there."))

(1.8) ((noise: door closing))

At line 3, the complainant directs the child to close the door, referring to the door tacitly (Fecha ai / "Close \{it\} there"). This constitutes a grammatically, pragmatically, and intonationally possibly complete TCU. Without waiting for a response from the child, the speaker immediately goes on to explicate the reference to the door by adding a porta ("the door"). This addition constitutes

brought to a possible completion, any explication of referents in the transition space is exposed. These "postpredicate" extensions are understood to be operating on the prior TCU, but they do so disjointedly and are marked (see CouperKuhlen \& Ono, 2007; Kim, 2007).

${ }^{9}$ During line 2, Lena's face can only be seen in profile on the video. From what can be seen, Lena simply holds her gaze on Mira and displays no signs of nonunderstanding (such as poking or tilting her head-cf. Seo \& Koshik, 2010). 
a grammatically contiguous incremental extension of the host TCU, now translatable as "Close. the door there." The addition of a porta ("the door") recompletes the turn constructional unit, and (in line 4), the child complies with the request.

So in the three languages under investigation, an explicit reference may be added to a TCU that is possibly complete in order to explicate something that was referred to tacitly. When the explicit reference fits into the grammatical object slot of the host TCU, the operation of explicating the referent is embedded in the progressive construction of a turn and, thus, masked.

Let's now turn to instances in which the added explicit reference functions as a grammatical subject of the host TCU. In these contexts, English differs from Russian and Brazilian Portuguese. This distinction is illustrated by Excerpt 12, taken from a call to a home birth helpline. At line 6, the call-taker (Clt) inquires about the caller's previous childbirth experiences.

Excerpt 12: Both of Them

$\operatorname{HB} 17(00: 21)$

01 Emi: I'm interested in having a ho:me birth

$02 \quad$ it's my thi:rd (.) chi:1 [d. ]

03 Clt: $\quad[\mathrm{mm}] \mathrm{hm}$

04 Emi: .hhh um straightforward- (0.2) well i- indu:ced:

$05 \quad(0.3)$ deliveries with the other two::=

06 Clt: $=\mathrm{O}: \mathrm{h}_{i}[$ Why ] were they indu:ced?=

07 Emi: $\quad[(\quad)]$

08 Emi: =Uh- eleven days la:te. Both of the:m:. .h Uh : : m

09 Clt: And did- Was that really late.=d'you knowi

At line 8, Emily initially does not make explicit what was (or were) "eleven days late." However, given the immediately preceding talk, the recipient would understand "eleven days late" as tacitly referring to "deliveries" (or "they"). Having reached the possible completion of her TCU, Emily goes on to explicate (and specify) the referent with "both of the:m:." This eliminates the possibility that "eleven days late" might only be referring to one of the deliveries (since having both deliveries induced exactly eleven days late seems unusual). Note that "both of the:m:" does not constitute a grammatically contiguous incremental extension of "eleven days late." Rather, the addition of the explicit reference exposes the initial response as having been in some way inadequate. Because of the relatively inflexible word order in English, which generally requires for grammatical subjects to be TCU-initial, the addition of the explicit reference that fulfills the role of a grammatical subject in the transition space exposes the operation of explicating a referent as repair. ${ }^{10}$

\footnotetext{
${ }^{10}$ It should be noted that transition space repair on an indexical reference may result in a grammatical construction called "right dislocation" (Quirk, Greenbaum, Leech, \& Svartvik, 1985), as in the following excerpt (line 3):

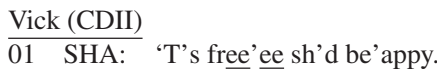

02 MIC: W[asn' hap p y. ]

03 NAN: [He- he's there ]evry night Vick

$04 \quad(0.4)$

05 MIC: Mm hm?

$06 \quad$ (1.2)

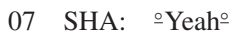


As discussed earlier, in Russian and Brazilian Portuguese, a grammatical subject may be placed at the end of a TCU (see Excerpts 7 and 8). This feature of the grammar of these languages makes it possible to explicate a tacit referent via an incremental extension of the host TCU, without engaging the machinery of repair (unlike in English), even when what is being added functions as a grammatical subject.

This is seen in Excerpt 13, taken from a telephone conversation between Greg and Vitya. Greg is watching a basketball game on television and is telling Vitya (who does not have access to the game) what he is seeing on the screen. A player just threw a free throw and scored.

Excerpt 13: Minnesota [Russian]

RP 6 (audio 7:50)

01 Greg: P^apal/

hit

$\{$ he $\}$ scored

02

$(0.5)$

03 Greg: Na adno achko vperedi:/ by one point ahead

\{They are\} one point ahead

04

05

Greg: $\mathrm{t} !=$ Minesota./

Minnesota

06

(0.5)

07

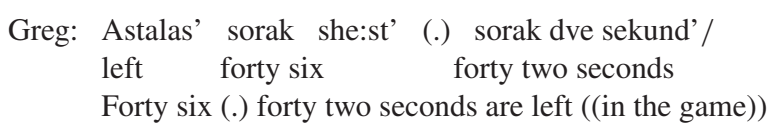

At line 3, Greg announces that one of the teams is "one point ahead." Produced with a unit-final intonation (marked with a slash on the transcript), this constitutes a possibly complete unit that tacitly refers to one of the teams. Since Vitya does not have visual access to the game playing on Greg's television, it might be unclear to him which team is in the lead (especially since the score is very close). When Vitya does not respond to the news (see the gap in line 4), Greg explicates the referent by providing a recognitional reference "Minnesota" to refer to one of the teams (line 5). The explicit reference form is an incremental extension of Greg's turn constructional unit, now translatable as "Minnesota is one point ahead." With the addition of "Minnesota," the TCU is again possibly complete and response ready.

Excerpt 14 is from a conversation between siblings who have been discussing Fernando's role on a university's search committee.

The relationship between transition space repair and right dislocation and what it might mean for "grammar for conversation" deserve further investigation (see, for example, Geluykens, 1994). 
Excerpt 14: The Committee [Portuguese]

01 Fer: Só tem eu de junior assim de tenure track. Only has me of Junior like of tenure track It's only me who's junior like tenure track.

02 (.)

03 Fer: $\quad$ E : :- mas eles são legais=eu gosto deles mas não And- but they are nice $=\mathrm{I}$ like them but no And- but they are nice $=$ I like them but there's no tem amizade assim. [E é tu]do pe-e eu sou o has friendship like. [And is a]ll tr- and I am the friendship of sorts. [And is a]ll tr- and I am the

05 Eug:

$$
\text { [Um hum ] }
$$

06 Fer: único de macro do comitê também. .h Além disso. only of macro of + the committee as well. .h Besides. only macro person on the committee as well. h Besides.

07 Eug: Mas é um pressão meio f::ogo num é:. But is a pressure half fire no is. But $\{$ it's $\}$ kinda strong pressure right.

08 Fer: Quê:?

What?

09 Eug: Num é uma pressão meio gra:nde. No is a pressure half big. Isn't $\{$ it $\}$ kind of a big pre:ssure.

10 (.)

11 Eug: [Você] ser o único de macro e ainda sê o único júnior. .h [You ] to be the only of macro and still be the only junior. [You ] being the only macro person and also the only junior one. .h

12 Fer: $[(\quad)]$

14 Fer: Não.

No.

At line 7, Eugenia produces an assessment of the situation referring to what exactly is being assessed tacitly: "But $\{$ it's $\}$ kinda strong pressure right." Following the assessment, Fernando initiates repair on it with an "open class" repair initiator Quê:?/"what?" (line 8) (Drew, 1997; Schegloff et al., 1977). In response (line 9), Eugenia repeats the assessment (but replaces the 
assessment terms ${ }^{11}$ ) without explicating the referent. After a micropause (line 10), she goes on to articulate what she had left as inferable: "You being the only macro person and also the only junior one" (line 11). This addition is a grammatically fitted increment to the preceding TCU.

To summarize, speakers may first design their turn to accomplish tacit referring and then, in the transition space, go on to explicate the referent by providing an explicit reference form. In Russian and Brazilian Portuguese, this remedial operation can be carried out via an incremental extension of the host TCU in a variety of grammatical environments. As speakers explicate referents that had been tacitly referred to, they recast the grammatical organization of the turn-in-progress, so that the turn in its entirety constitutes again a possibly complete TCU. In English, this seems possible in fewer grammatical environments (e.g., when the added explicit reference functions as a grammatical object, but not a subject, of the host TCU).

\section{INTERACTIONAL ACCOMPLISHMENTS OF REFERENCE EXPLICATION}

Now that we have described the operation of explicating tacit references without engaging repair machinery, we turn to a discussion of its interactional payoffs. In the following, we examine several interactional outcomes of this referent-explicating operation.

First, we already saw (in Excerpt 13) that the addition of an explicit reference may serve to resolve a potential ambiguity. Beyond that, notice that the explicit reference here is added after a substantial gap (line 4), where a news uptake from the recipient is due. By extending his turn with a grammatically fitted increment, Greg converts an interturn gap into an intra-TCU pause (Sacks et al., 1974) and, in doing so, masks the turn transition problem and a potential problem of alignment by treating it as a problem of understanding (cf. Pomerantz, 1984b). Similarly to what is discussed in Bolden, Mandelbaum, and Wilkinson (2012/this volume), an explication of a referent in an incremental extension of a host TCU could be a practice for pursuing a response without exposing the lack of response as a problem (as other forms of pursuit might do).

Excerpt 14 is another instance when this remedial operation is used in pursuit of a response from the addressee. Following Eugenia's assessment of Fernando's situation (at line 7), an agreement (or disagreement) is due from him (Pomerantz, 1984a). Instead, Fernando first initiates repair on the assessment (line 8), which may be a harbinger of upcoming disagreement (Schegloff, 1997; Schegloff et al., 1977). Eugenia's repaired assessment (line 9) is not immediately responded to (see the gap at line 10), and Eugenia goes on to explicate what she had referred to tacitly, thus treating the lack of response as indexing a problem of understanding. Following another gap, Fernando disagrees with the assessment (line 14). These two instances from Russian and Brazilian Portuguese suggest that the operation of explicating a tacit reference may be used as a rather covert method for pursuing a response from the addressee.

Second, an incrementally added explicit reference may add specificity to what otherwise would have been understood by the tacit reference-and this may have some interactional payoffs as well. In Excerpt 15, Ben is telling Ella about some out-of-town visiting musicians. They are

\footnotetext{
${ }^{11}$ The problem with the initial assessment term might be that the expression é ( . . ) f:: ogo" is similar to the vulgar, but more common, é foda (meaning "it's hard"). The new version (at line 9) avoids this association.
} 
hosted by Ben's sister (“she” in line 1) but are staying at Ben's house. Ben is somewhat jokingly complaining about this situation.

Excerpt 15: Three [Russian]

RP7 (3:30)

01 Ben: .hh Ana ix xorosho prinima $=\mathrm{a}=$ va- budut she them well hosts PRT will [ $3^{\text {rd }}-$ Plural $]$

She's hosting them nicely=but $\{$ they $\}$ will

02

zh[it' [ani budut u nas]/

live they will with us

they will be staying with us

03 Ella: [k- [.h hhh ]

04 Ben: Nu pravda u në tozhe budut zhit'/

PRT truth with her also will [ $3^{\text {rd }}$ Plural] live

But truthfully \{they\}'ll be staying with her also

05 Ella: $\quad$ Mh-mu:h, $/=$

06 Ben: $=$ Troe $/$

three

Three of them

07 Ella: Mh $[\mathrm{mhm} /$

08 Ben: [A u nas ad- adna/ No zato s vialachel'ju/

PRT with us one PRT PRT with viola

And one with us/ But with a viola

09 Ella: Nu ja:sna/ Zdorava/

PRT clear great

I see/ That's great

Ben first states (at lines 1-2) that the visitors will be staying at his house. At line 4, however, he backs off this claim asserting that some of them will also be staying with his sister. Line 4 tacitly refers to an unspecified number of the visitors and is a possibly complete TCU. ${ }^{12}$ Following a continuer from Ella (line 5), Ben adds an incremental extension to his TCU that explicitly formulates who is being referred to: troe ("three of them," line 6). This formulation modifies what would otherwise be understood from the tacit referring at line 4 (i.e., some of the visitors) with a more precise formulation "three of them" (cf. Drew, 2003). Ben then goes on to state that only one person will be staying at his house (line 8). Here, the speaker exploits grammatical flexibility afforded by the language to play up his complaint: i.e., by first implying that all visitors will be staying with him ("they" in lines 1-2), then indicating that some will be staying with his sister (tacit reference at line 4), and only then revealing (line 6) that three of the four visitors will be staying there and only one at his house (at line 8). So tacit referring allows the speaker to make an ambiguous claim, which, as it turns out, overstates his case for the purposes of complaining. He

\footnotetext{
${ }^{12}$ In Russian, the verb "will live" (budut zhit) is marked for the third person plural or "they."
} 
then backs off of it rather subtly by incrementally extending his TCU with an explicit reference that significantly diminishes the complainability of the situation.

A speaker may also go on to explicate a referent in order to upgrade the action of the turn. In Excerpt 16, two women, Dina and Tanya, are talking about a wedding Dina's sons have been invited to. At line 1, Tanya is responding to an earlier question about whether the groom ("he" at line 1) invited her daughters to the wedding (in fact, he did not).

Excerpt 16: His Madam [Russian]

RP 4 (audio 2:15)

01 TAN: $\quad \mathrm{Nu}$ vot $<\mathrm{Nu}=$ kuda: kak on budet priglashat' devcho, nak/

PRT PRT PRT where how he will invite girls

How can he possibly invite the girls

02

ty che[vo/

you what

what are you $\{$ saying

03 DIN:

$[\mathrm{Mm}[\mathrm{mm}:$

04 TAN

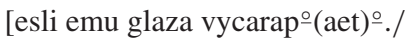
if him eyes scratch-out [Future- $3^{\text {rd }}$-Sing]

if $\{$ she\} will scratch his eyes out

05

(.)

06 DIN: $\quad \mathrm{Mm} \mathrm{mm}$

07 TAN: £Evo/£

his

His ((other half))

08

(.)

09 TAN: £Madam/£

Madam

Madam

10 TA?: .h

11 DIN: $[\mathrm{Mm} \mathrm{mm}$

12 TAN: $\quad[\mathrm{Nu}$ vot

PRT PRT

Anyways, ... ((return to an earlier topic))

At line 4, Tanya claims that "she" (or "the bride") will scratch the groom's eyes out if he were to invite Tanya's daughters. The reference to "the bride" is achieved tacitly: by using an idiomatic expression that conveys jealousy most readily attributable to the bride, as well as by marking the verb morphologically for she or he. Tanya's turn is grammatically, pragmatically, and intonationally possibly complete at the end of line 4. Tanya's explanation for why her daughters are not invited to the wedding is critical of the bride; a preferred response from Dina would accept the explanation and/or affiliate with the criticism (Pomerantz, 1984a). However, following 
a micropause (line 5), Dina simply produces a continuer (line 6), which treats Tanya's preceding turn as an incomplete action (Schegloff, 1982) and, importantly, fails to affiliate or align with Tanya's position. In the absence of action-appropriate uptake from Dina, Tanya goes on to extend her turn by articulating the person reference-evo (translatable as "his" or, in this context, "his other half," line 7). In Russian, evo is an incremental extension of Tanya's TCU. The resulting turn is again grammatically, pragmatically, and intonationally possibly complete and translatable as "His other half will scratch his eyes out." The incremental addition of the explicit reference form treats the tacit referring (at line 4) as possibly problematic and treats the lack of actionappropriate response from Dina as attributable to a problem of understanding (see Bolden et al., 2012 /this issue).

When Dina does not immediately respond (see the micropause at line 8), Tanya goes on to further unpack the reference by adding "Madam" (line 9). This is a further increment that results, again, in a possibly complete TCU, now translatable as "His madam will scratch his eyes out." The addition of "Madam" — an alternative recognitional reference form (Stivers, 2007) describes the referent (the bride) in a rather derogatory way and, thus, upgrades the criticism perhaps in search of a more affiliative response from Dina. Dina, however, simply produces another continuer (line 11), withholding affiliation once again, and, simultaneously, Tanya closes the topic (line 12). So an explication of a tacit reference via an incremental extension is a rather subtle practice for modulating or fine-tuning the action of the turn: here, for upgrading a criticism.

\section{CONCLUSIONS}

In this article, we have outlined grammatical resources that make it possible for speakers to formulate explicitly something that had been referred to tacitly and to do so without engaging in the activity of repair. We showed how two aspects of grammar - the availability of tacit referring and a flexible word order-enable speakers to carry out this repair-like operation in a covert or embedded fashion, in a way that is akin to embedded self-correction (Jefferson, 1987), a practice we know little about (but see Lerner, 1994).

We have shown that in languages like Russian and Brazilian Portuguese (and to a lesser extent in English), this referent-explicating operation can be accomplished via a grammatically fitted increment to the host turn constructional unit. In this respect, this report extends existing research into the machinery and interactional functions of increments (see, for example, Couper-Kuhlen \& Ono, 2007; Ford et al., 2002; Schegloff, 2000). We show that incrementing an explicit reference formulation is a practice for accomplishing a variety of actions: such as, disambiguating or specifying a potentially ambiguous reference, pursuing recipient response, or in some way finetuning the action of the turn (e.g., backing off an implied claim or upgrading a criticism). Thus, incrementing an explicit reference form is a flexible tool available to speakers of some languages for doing a variety of rather delicate actions.

An examination of practices of tacit referring and ways in which tacit references get explicated across different languages offers a window into how grammars work in and shape social interaction. We have seen that a likely universal conversational task of remediating a problematic reference is profoundly shaped by the grammatical affordances of the language. Furthermore, the sorts of actions reference remediation may accomplish (beyond dealing with problems of understanding or speaking) may be also shaped by what is allowable by the grammar. 


\section{REFERENCES}

Bolden, G. B. (2009). Implementing delayed actions. In J. Sidnell (Ed.), Conversation analysis: Comparative perspectives (pp. 326-354). Cambridge, England: Cambridge University Press.

Bolden, G. B., Mandelbaum, J., \& Wilkinson, S. (2012/this issue). Pursuing a response by repairing an indexical reference. Research on Language and Social Interaction, 45, 137-155.

Couper-Kuhlen, E., \& Ono, T. (2007). "Incrementing" in conversation. A comparison of practices in English, German, and Japanese. Pragmatics, 17, 513-552.

Cyrino, S. M. L. (2004). On the existence of null complement anaphora in Brazilian Portuguese. Revista Letras, 63, 97-117.

Cyrino, S. M. L., \& Matos, G. (2002). VP ellipsis in European and Brazilian Portuguese: A comparative analysis. Journal of Portuguese Linguistics, 1, 177-195.

Drew, P. (1997). "Open" class repair initiators in response to sequential sources of troubles in conversation. Journal of Pragmatics, 28, 69-101.

Drew, P. (2003). Precision and exaggeration in interaction. American Sociological Review, 68, 917-938.

Duarte, M. E. L. (2003). A evolução na representação do sujeito pronominal em dois tempos [The evolution in the representation of the pronominal subject in two times]. In M. C. Paiva \& M. E. L. Duarte (Eds.), Mudança lingüística em tempo real [Linguistic change in real time] (pp. 115-128). Rio de Janeiro, Brazil: Contra Capa.

Egbert, M. M., Golato, A., \& Robinson, J. D. (2009). Repairing reference. In J. Sidnell (Ed.), Conversation analysis: Comparative perspectives (pp. 104-132). Cambridge, England: Cambridge University Press.

Ford, C. E., Fox, B. A., \& Thompson, S. A. (2002). Constituency and the grammar of turn increments. In C. E. Ford, B. A. Fox, \& S. A. Thompson (Eds.), The language of turn and sequence (pp. 14-38). Oxford, England: Oxford University Press.

Ford, C. E., \& Thompson, S. A. (1996). Interactional units in conversation: Syntactic, intonational, and pragmatic resources for the management of turns. In E. Ochs, E. A. Schegloff, \& S. A. Thompson (Eds.), Interaction and grammar (pp. 134-184). Cambridge, England: Cambridge University Press.

Fox, B. A., Hayashi, M., \& Jasperson, R. (1996). Resources and repair: A cross-linguistic study of syntax and repair. In E. Ochs, E. A. Schegloff, \& S. A. Thompson (Eds.), Interaction and grammar (pp. 185-237). Cambridge, England: Cambridge University Press.

Geluykens, R. (1994). The pragmatics of discourse anaphora in English: Evidence from conversational repair. New York, NY: Mouton de Gruyter.

Goodwin, C. (1979). The interactive construction of a sentence in natural conversation. In G. Psathas (Ed.), Everyday language: Studies in ethnomethodology (pp. 97-121). New York, NY: Irvington.

Gordishevsky, G., \& Avrutin, S. (2003). Subject and object omissions in child Russian. Paper presented at the Israel Association for Theoretical Linguistics 19, Ben Gurion University of the Negev, Beersheva, Israel.

Grenoble, L. A. (2001). Conceptual reference points, pronouns and conversational structure in Russian. Glossos, 1. Retrieved from http://www.seelrc.org/glossos/issues/1/grenoble.pdf

Hacohen, G., \& Schegloff, E. A. (2006). On the preference for minimization in referring to persons: Evidence from Hebrew conversation. Journal of Pragmatics, 38, 1305-1312.

Heritage, J. (1984). A change-of-state token and aspects of its sequential placement. In J. M. Atkinson \& J. Heritage (Eds.), Structures of social action: Studies in conversation analysis (pp. 299-345). New York, NY: Cambridge University Press.

Holmberg, A. (2005). Is there a little pro? Evidence from Finnish. Linguistic Inquiry, 36, 533-564.

Jefferson, G. (1981). The abominable $n e$ ? An exploration of post-response pursuit of response. In P. Shroder (Ed.), Sprache der gegenwaart (pp. 53-88). Düsseldorf, Germany: Pedagogischer Verlag Schwann.

Jefferson, G. (1987). On exposed and embedded correction in conversation. In G. Button \& J. R. E. Lee (Eds.), Talk and social organization (pp. 86-100). Philadelphia, PA: Multilingual Matters.

Kato, M. A. (2000). The partial pro-drop nature and the restricted VS order in Brazilian Portuguese. In M. A. Kato \& E. V. Negrao (Eds.), Brazilian Portuguese and the null subject parameter (pp. 223-258). Madrid, Spain: Vervuert Iberoamericana.

Kim, K.-h. (2007). Sequential organization of post-predicate elements in Korean conversation: Pursuing uptake and modulating action. Pragmatics, 17, 573-603.

Lerner, G. H. (1994). Responsive list construction: A conversational resource for accomplishing multifaceted social action. Journal of Language and Social Psychology, 13, 20-33. 
Levinson, S. C. (2007). Optimizing person reference - Perspectives from usage on Rossel Island. In N. J. Enfield \& T. Stivers (Eds.), Person reference in interaction: Linguistic, cultural and social perspectives (pp. 29-72). Cambridge, England: Cambridge University Press.

Magalhães, T., \& Santos, A. L. (2006). As respostas verbais e a freqüência de sujeito nulo na aquisição do Português Brasileiro e do Português Europeu [Verbal responses and the frequency of null subject in the acquisition of Brazilian Portuguese and European Portuguese]. Letras de Hoje [Today's Letters], 41, 179-193.

McShane, M. J. (2002). Unexpressed objects in Russian. Journal of Slavic Linguistics, 10, 291-328.

Oh, S.-Y. (2005). English zero anaphora as an interactional resource. Research on Language and Social Interaction, 38 , 267-302.

Oh, S.-Y. (2006). English zero anaphora as an interactional resource II. Discourse Studies, 8, 817-846.

Oh, S.-Y. (2007). Overt reference to speaker and recipient in Korean. Discourse Studies, 9, 462-492.

Ono, T., \& Thompson, S. A. (1997). Deconstructing "zero anaphora" in Japanese. Berkeley Linguistic Society, 23, 481-491.

Pomerantz, A. (1984a). Agreeing and disagreeing with assessments: Some features of preferred/dispreferred turn shapes. In J. M. Atkinson \& J. Heritage (Eds.), Structures of social action: Studies in conversation analysis (pp. 57-101). New York, NY: Cambridge University Press.

Pomerantz, A. (1984b). Pursuing a response. In J. M. Atkinson \& J. Heritage (Eds.), Structures of social action (pp. 152-164). Cambridge, England: Cambridge University Press.

Quirk, R., Greenbaum, S., Leech, G., \& Svartvik, J. (1985). A comprehensive grammar of the English language. London, England: Longman.

Sacks, H., Schegloff, E. A., \& Jefferson, G. (1974). A simplest systematics for the organization of turn-taking for conversation. Language, 50, 696-735.

Schegloff, E. A. (1982). Discourse as an interactional achievement: Some uses of "uh huh" and other things that come between sentences. In D. Tannen (Ed.), Analyzing discourse: Text and talk (pp. 71-93). Washington, DC: Georgetown University Press.

Schegloff, E. A. (1996a). Some practices for referring to persons in talk-in-interaction: A partial sketch of a systematics. In B. A. Fox (Ed.), Studies in anaphora (pp. 437-485). Philadelphia, PA: John Benjamins Publishing.

Schegloff, E. A. (1996b). Turn organization: One intersection of grammar and interaction. In E. Ochs, E. A. Schegloff, \& S. A. Thompson (Eds.), Interaction and grammar (pp. 52-133). Cambridge, England: Cambridge University Press.

Schegloff, E. A. (1997). Practices and actions: Boundary cases of other-initiated repair. Discourse Processes, 23, 499-545.

Schegloff, E. A. (2000, November). On turns' possible completion, more or less: Increments and trail-offs. Paper presented at the 2000 Annual Conference of the National Communication Association, Seattle, WA.

Schegloff, E. A. (2007). Conveying who you are: The presentation of self, strictly speaking. In N. J. Enfield \& T. Stivers (Eds.), Person reference in interaction: Linguistic, cultural, and social perspectives (pp. 123-148). Cambridge, England: Cambridge University Press.

Schegloff, E. A., Jefferson, G., \& Sacks, H. (1977). The preference for self-correction in the organization of repair in conversation. Language, 53, 361-382.

Seo, M.-S., \& Koshik, I. (2010). A conversation analytic study of gestures that engender repair in ESL conversational tutoring. Journal of Pragmatics, 42, 2219-2239.

Silva, G. V. (2001). Word order in Brazilian Portuguese. Berlin, Germany; New York, NY: Mouton de Gruyter.

Stivers, T. (2007). Alternative recognitionals in person reference. In N. J. Enfield \& T. Stivers (Eds.), Person reference in interaction: Linguistic, cultural, and social perspectives (pp. 73-96). Cambridge, England: Cambridge University Press.

Turk, M. J. (2000). Word order in Russian conversation: A quantitative study (Unpublished master's thesis). University of California, Santa Barbara, CA.

Yokoyama, O. T. (1986). Discourse and word order. Amsterdam, The Netherlands: Benjamins.

Zdorenko, T. (2009). Subject omission in Russian: A study of the Russian National Corpus. In S. T. Gries, S. Wulff, \& M. Davies (Eds.), Corpus-linguistic applications: Current studies, new directions (Vol. 71, pp. 119-133). Amsterdam, The Netherlands: Rodopi. 